\title{
Antidepressant stimulation of CDP-diacylglycerol synthesis does not require monoamine reuptake inhibition
}

\author{
Marwa A Aboukhatwa ${ }^{2}$, Ashiwel S Undieh ${ }^{1 *}$
}

\begin{abstract}
Background: Recent studies demonstrate that diverse antidepressant agents increase the cellular production of the nucleolipid CDP-diacylglycerol and its synthetic derivative, phosphatidylinositol, in depression-relevant brain regions. Pharmacological blockade of downstream phosphatidylinositide signaling disrupted the behavioral antidepressant effects in rats. However, the nucleolipid responses were resistant to inhibition by serotonin receptor antagonists, even though antidepressant-facilitated inositol phosphate accumulation was blocked. Could the neurochemical effects be additional to the known effects of the drugs on monoamine transmitter transporters? To examine this question, we tested selected agents in serotonin-depleted brain tissues, in PC12 cells devoid of serotonin transporters, and on the enzymatic activity of brain CDP-diacylglycerol synthase - the enzyme that catalyzes the physiological synthesis of CDP-diacylglycerol.

Results: Imipramine, paroxetine, and maprotiline concentration-dependently increased the levels of CDPdiacylglycerol and phosphatidylinositides in PC12 cells. Rat forebrain tissues depleted of serotonin by pretreatment with $p$-chlorophenylalanine showed responses to imipramine or maprotiline that were comparable to respective responses from saline-injected controls. With fluoxetine, nucleolipid responses in the serotonin-depleted cortex or hippocampus were significantly reduced, but not abolished. Each drug significantly increased the enzymatic activity of CDP-diacylglycerol synthase following incubations with cortical or hippocampal brain tissues.

Conclusion: Antidepressants probably induce the activity of CDP-diacylglycerol synthase leading to increased production of CDP-diacylglycerol and facilitation of downstream phosphatidylinositol synthesis.

Phosphatidylinositol-dependent signaling cascades exert diverse salutary effects in neural cells, including facilitation of BDNF signaling and neurogenesis. Hence, the present findings should strengthen the notion that modulation of brain phosphatidylinositide signaling probably contributes to the molecular mechanism of diverse antidepressant medications.
\end{abstract}

\section{Background}

Neither the pathophysiology of depression nor the mechanism of action of various antidepressant agents is fully understood. Accumulating evidence implicates brain phospholipid metabolism in the actions of diverse antidepressant drugs [1-3]. For example, diverse antidepressant agents increase the cellular production of CDPdiacylglycerol and its synthetic derivative, phosphatidylinositol, in depression-relevant regions of the rat brain

\footnotetext{
* Correspondence: ashiwel.undieh@jefferson.edu

'Laboratory of Integrative Neuropharmacology, Department of

Pharmaceutical Sciences, Thomas Jefferson University School of Pharmacy, Philadelphia, Pennsylvania, USA
}

(c) 2010 Aboukhatwa and Undieh; licensee BioMed Central Ltd. This is an Open Access article distributed under the terms of the Creative Commons Attribution License (http://creativecommons.org/licenses/by/2.0), which permits unrestricted use, distribution, and reproduction in any medium, provided the original work is properly cited.
[2]. Moreover, blockade of downstream inositol phospholipid signaling results in significant disruption of behavioral antidepressant effects in the rat forced swim model of depression [3]. These and related observations have reawakened interest in neural phospholipid systems as potentially crucial contributors to the pathophysiology of depression and/or the mechanism of action of antidepressant drugs.

CDP-diacylglycerol is a crucial intermediate in the synthesis of phosphatidylinositol and related signaling mediators. Enhanced production of CDP-diacylglycerol can be expected to lead to increased synthesis of phosphatidylinositides. Hence, blood platelets incubated with 
different antidepressants show higher levels of phosphatidylinositides compared to control platelets, and this newly synthesized pool of phosphatidylinositides could be further available for receptor-coupled cell signaling $[4,5]$. Another recent study also showed that different antidepressant drugs induce phosphatidylinositide synthesis and facilitate subsequent serotonergic-stimulated accumulation of inositol phosphate second messengers [3]. This report also showed that selective blockade of phosphoinositide-linked $5 \mathrm{HT}_{2}$ serotonin receptors inhibited the effects of antidepressant drugs on inositol phosphate accumulation, but the drug effects on CDPdiacylglycerol production or phosphoinositide synthesis were not substantially reduced by $5 \mathrm{HT}_{2}$ antagonist treatment. These observations suggest that the drug effects on CDP-diacylglycerol and phosphatidylinositide synthesis involve a mechanism that may not depend on increased synaptic serotonin action. Clarifying such a mechanism would increase understanding of depression pathology, and could lead to the development of new and better treatment strategies.

The present study was directed at testing the hypothesis that the nucleolipid effects of antidepressants on CDP-diacylglycerol and its derived inositol phospholipids are substantially independent of the known effects of the drugs to enhance synaptic serotonin levels. We evaluated the neurolipid effects of a selection of drugs in tissues depleted of serotonin, and in neuron-like PC12 cells that are deficient in receptors and transporters for serotonin or norepinephrine [6]. Upon observing that the drugs retained their ability to acutely increase nucleolipid synthesis, we explored if the drugs might directly enhance the enzymatic activity of CDP-diacylglycerol synthase, the enzyme that synthesizes CDP-diacylglycerol. The findings suggest that various antidepressant agents are capable of stimulating the activity of CDP-diacylglycerol, which might explain the enhancing effects of the agents on CDP-diacylglycerol synthesis and phosphatidylinositide production.

\section{Methods}

Animals

Male inbred C57BL/6 mice weighing 25-30 g were purchased from Harlan (Indianapolis, Indiana) and housed 5 per cage. Male Sprague-Dawley rats weighing 225-250 g were purchased from Zivic Laboratories (Pittsburgh, PA) and housed three per cage. Animals were kept for at least three days before use and housing was on a 12-hour light/dark cycle in climate-controlled facilities. Food and water were freely accessible to each cage of animals. Protocols for the care and use of the animals were approved by the Institutional Animal Care and Use Committee and conformed to the National Institutes of Health Guide for the Care and Use of Laboratory Animals.

\section{Drugs and chemicals}

Buffer reagents and all drugs used were purchased from Sigma-Aldrich (St. Louis, MO). For the neurolipid (CDP-diacylglycerol and phosphatidylinositide) assays and the enzyme activity experiments, test drugs were dissolved in HEPES bicarbonate (HB) buffer, while for the cell culture experiments the drugs were dissolved in phosphate buffered saline. Drugs were prepared fresh before use.

\section{$p$-Chlorophenylalanine induction of brain serotonin depletion}

To deplete rat brain tissues of serotonin content, the animals were administered the tryptophan hydroxylase inhibitor, p-chlorophenylalanine (PCPA) at the dosage of $150 \mathrm{mg} / \mathrm{kg}$ daily for three days, followed by a 12-h washout period prior to testing. Control animals received injections of saline. This regimen of PCPA is known to result in depletion of $85-95 \%$ of forebrain serotonin content without affecting the catecholamines [7-9].

\section{Measurement of CDP-diacylglycerol synthesis in serotonin-depleted brain tissues}

CDP-diacylglycerol levels in brain tissue preparations were measured as previously described $[2,10]$. For the present study, hippocampal or frontal cortical tissues were prepared from saline-injected (control) and PCPApretreated rats and processed in parallel. Following a 30-min prelabeling incubation with $0.6 \mu \mathrm{M} 5-\left[{ }^{3} \mathrm{H}\right]$ cytidine $(20 \mathrm{Ci} / \mathrm{mmole}$, American Radiolabeled Chemicals, St. Louis, MO), aliquots of slices from each pretreatment group were incubated with various concentrations of selected antidepressant agents for $90 \mathrm{~min}$, and accumulated $\left[{ }^{3} \mathrm{H}\right] \mathrm{CDP}$-diacylglycerol measured as previously described [10].

\section{Measurement of CDP-diacylglycerol and}

\section{phosphatidylinositide synthesis in PC12 cells}

PC12 cells obtained from ATCC (Manassas, VA) were maintained in RPMI-1640 Medium supplemented with $5 \%$ fetal bovine serum, $10 \%$ horse serum and $2 \mathrm{mM} \mathrm{L}-$ glutamine at $37^{\circ} \mathrm{C}$ with $5 \% \mathrm{CO}_{2}$ aeration. The cells were cultured on poly-D-lysine coated plates until reaching approximately $80 \%$ confluency and then transferred to Neurobasal medium (Neurobasal+N2 supplement +glutamine) one day before the assay. Cells in wells of a 24well plate were labeled with $1.5 \mu \mathrm{Ci}\left[5-{ }^{3} \mathrm{H}\right]$ cytidine (20 $\mathrm{Ci} / \mathrm{mmol}$; ARC, St. Louis, MO) for $30 \mathrm{~min}$ to generate a pool of radiolabeled cytidine triphosphate (CTP). After addition of $5 \mathrm{mM} \mathrm{LiCl}$, solutions of test drugs were added to the cells at indicated concentrations and incubation continued for $3 \mathrm{~h}$. To terminate the reaction, 1.5 $\mathrm{ml}$ of chloroform-methanol-1 M HCl (100:200:1) was added with mixing. The lipids were extracted by partitioning to the chloroform layer as described [10,11]; aliquots thereof were quantitatively transferred to 
polypropylene tubes and dried overnight at room temperature. Biosafe scintillation cocktail was added to each sample and the radioactivity determined by liquid scintillation. The radioactivity in each sample corresponds to $\left[{ }^{3} \mathrm{H}\right] \mathrm{CDP}$-diacylglycerol as characterized in previous studies $[10,12,13]$.

For the assay of phosphatidylinositol synthesis, PC12 cells cultured as described above were labeled for one hour with $1.5 \mu \mathrm{Ci}\left[{ }^{3} \mathrm{H}\right]$ inositol $(20 \mathrm{Ci} / \mathrm{mmol}$; ARC, St. Louis, MO). Subsequent drug treatments were maintained for an incubation period of $3 \mathrm{~h}$, followed by extraction and quantitation of the inositol phospholipids as described [10,11].

\section{Measurement of CDP-diacylglycerol synthase activity}

CDP-diacylglycerol synthase activity was assayed in mouse brain membrane preparations according to previously described methods with minor modifications [14-16]. Mice were rapidly decapitated and the desired tissues dissected, chopped into $350-\mu \mathrm{m}$ slices, and washed thrice with calcium-free $\mathrm{HB}$ buffer. Aliquots of tissue slices corresponding to approximately $500 \mu \mathrm{g}$ protein were distributed into tissue culture wells containing $450 \mu \mathrm{l} \mathrm{HB}$ buffer and incubated at $37^{\circ} \mathrm{C}$. Various concentrations of each test drug in $50 \mu \mathrm{l}$ volumes were added to appropriate tubes and incubation continued for $3 \mathrm{~h}$. Afterwards, the tissues were transferred into cold Tris lysis buffer ( $\mathrm{pH} 7.8$ ) containing a cocktail of protease inhibitors (Sigma-Aldrich, St. Louis, MO) and lysed by gentle homogenization. Cell debris was removed by centrifugation $\left(550 \times \mathrm{g}, 10 \mathrm{~min}\right.$, at $\left.4^{\circ} \mathrm{C}\right)$ and protein concentration of the membrane preparations was determined by the Bradford method. Equal aliquots of $25 \mu \mathrm{g}$ membrane protein were preincubated for 25 min with $3 \mu \mathrm{M} 5-\left[{ }^{3} \mathrm{H}\right] \mathrm{CTP}$ (specific activity $13.9 \mathrm{Ci} /$ mmol; Moravek Biochemicals, Brea, CA) in a $50-\mu \mathrm{l}$ reaction mixture that contained $0.1 \mathrm{M}$ Tris- $\mathrm{HCl} \mathrm{pH} \mathrm{7.5,} 0.2$ $\mathrm{M} \mathrm{KCl}, 1 \mathrm{mg} / \mathrm{ml}$ bovine serum albumin, $0.1 \%$ Triton $\mathrm{X}$ $100,0.25 \mathrm{mM}$ dithiothreitol, and $200 \mu \mathrm{M}$ 1,2-dioleoylsn-glycero-3-phosphate. The reaction was started by the addition of $10 \mathrm{mM} \mathrm{MgCl}$ and stopped after $20 \mathrm{~min}$ by the addition of chloroform: methanol: $10 \mathrm{M} \mathrm{HCl}$ $(1: 2: 0.02, \mathrm{v} / \mathrm{v})$. After incubating at room temperature for $30 \mathrm{~min}$ to extract formed $\left[{ }^{3} \mathrm{H}\right] \mathrm{CDP}$-diacylglycerol, the amount of the incorporated radioactivity was determined by liquid scintillation counting. Assayed enzyme activity was linear with time up to at least $30 \mathrm{~min}$ and with protein concentration up to at least $50 \mu \mathrm{g}$. One unit of CDP-diacylglycerol synthase activity was defined as the amount of the enzyme that catalyzed the formation of one nanomole of CDP-diacylglycerol per minute.

\section{Data analysis}

Neurolipid data were calculated as $\mathrm{dpm} / \mathrm{mg}$ protein. Each set of data was normalized by taking percentages relative to control incubations that excluded drug treatments. Data from two or three separate runs of the experiments were then pooled for statistical analysis and graphical representation as shown. Similarly, enzyme activity data were normalized against each day and tissue controls, and the data pooled for analysis. Statistical analyses were by One-Way ANOVA followed with posthoc Tukey tests to compare all possible pairs of group means or the Dunnett test to compare each treatment mean to its respective control group as indicated in the figure legends. Statistical comparisons were considered significant at $\mathrm{p}<0.05$ or better.

\section{Results}

Effects of serotonin depletion on the effectiveness of various antidepressant agents

Control and serotonin-depleted tissues from the rat hippocampus or frontal cortex were tested for CDP-diacylglycerol responses to various antidepressant agents. The tissue slices were prelabeled with $\left[{ }^{3} \mathrm{H}\right]$ cytidine and then incubated with maximally effective concentrations of the antidepressant drugs fluoxetine (FLX, $100 \mu \mathrm{M})$, imipramine (IMI, $300 \mu \mathrm{M}$ ), or maprotiline (MAP, $100 \mu \mathrm{M}$ ); these dose selections were based on previously published studies with brain slice preparations [2,3]. While similar results were obtained in the hippocampus and frontal cortex, the results for the frontal cortex are shown in Fig. 1. Imipramine, fluoxetine, or maprotiline induced significant accumulations of CDP-diacylglycerol in the saline-pretreated control tissues as expected. Tissues depleted of serotonin also gave significant responses to the antidepressant agents, although the responses to fluoxetine in the frontal cortex and to fluoxetine and maprotiline in the hippocampus were significantly but partially (21-32\%) reduced in $p$-chlorophenylalanine (PCPA)-pretreated tissues. The concentration and conditions of PCPA treatment in these experiments are known to result in practically complete depletion of serotonin from the tissues [7-9].

Antidepressant drugs increase the synthesis of CDPdiacylglycerol and phosphatidylinositides in PC12 cells PC12 cells prelabeled with $\left[{ }^{3} \mathrm{H}\right]$ cytidine were incubated with different concentrations of antidepressant drugs ranging from $0.1 \mu \mathrm{M}$ to $300 \mu \mathrm{M}$ and the accumulation of CDP-diacylglycerol assayed after $3 \mathrm{~h}$. The results are shown in Fig. 2. Imipramine (tricyclic antidepressant), maprotiline (norepinephrine and serotonin reuptake inhibitor), and paroxetine (selective serotonin reuptake inhibitor) each significantly and concentration-dependently increased the levels of CDP-diacylglycerol in the PC12 cells [ANOVA, $\mathrm{p}<0.0001$ ]. Based on the posthoc Dunnett tests, significant effects were obtained at concentrations of $30 \mu \mathrm{M}$ and higher.

To test if antidepressant-induced increases in CDPdiacylglycerol translated into enhanced synthesis of 

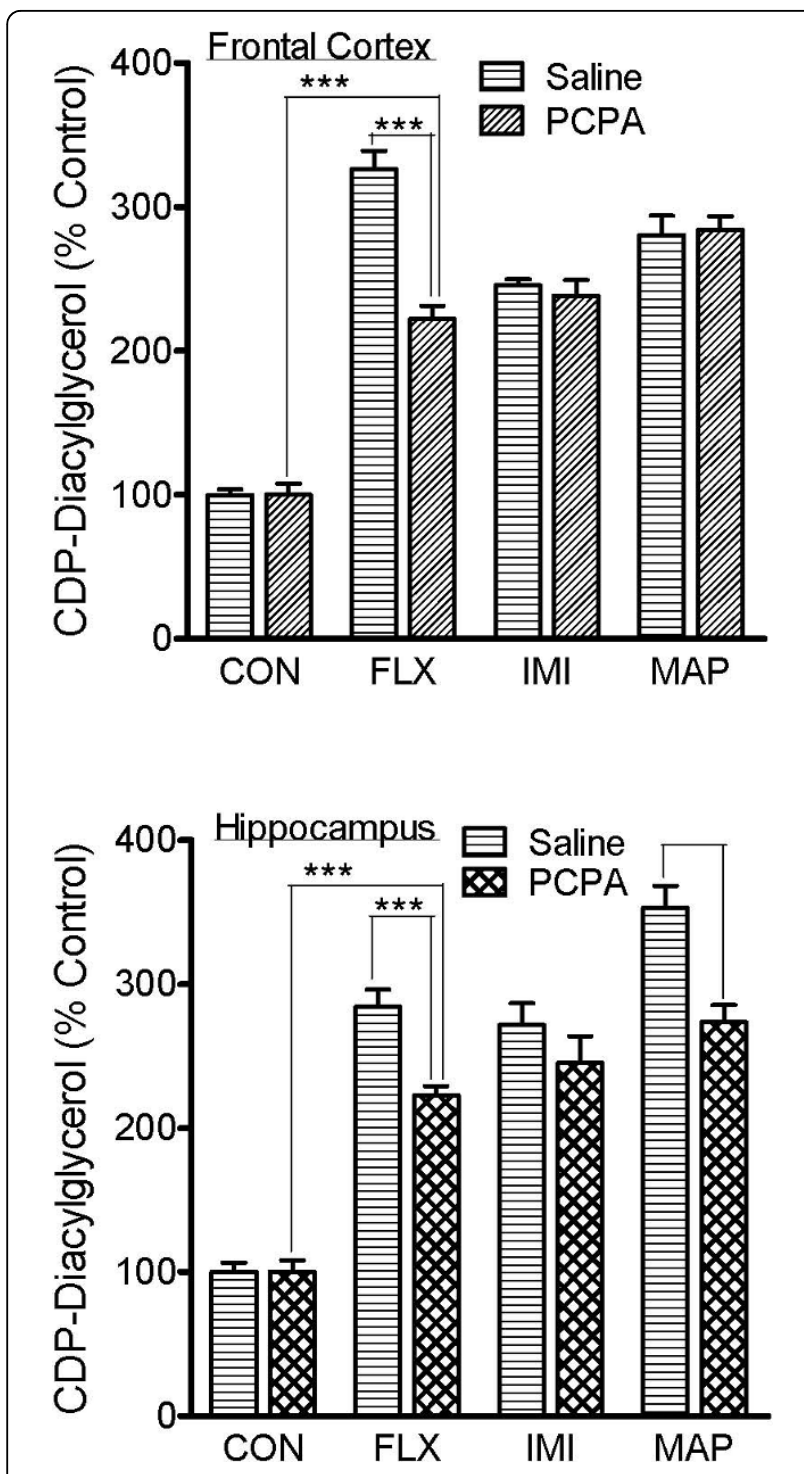

Figure 1 Effects of PCPA-induced serotonin depletion on antidepressant stimulation of CDP-diacylglycerol synthesis in brain tissue. Brain slices were prepared from the frontal cortex or hippocampus tissues of saline-injected control rats or animals that had been administered $p$-chlorophenylalanine (PCPA) to deplete endogenous serotonin stores. The tissue slices were labeled with $\left[{ }^{3} \mathrm{H}\right]$ cytidine and then incubated with predetermined concentrations of the antidepressant drugs fluoxetine (FLX, $100 \mu \mathrm{M}$ ), imipramine (IMI, $300 \mu \mathrm{M})$, or maprotiline (MAP, $100 \mu \mathrm{M})$. After $90 \mathrm{~min}$, accumulated $\left[{ }^{3} \mathrm{H}\right] \mathrm{CDP}$-diacylglycerol was measured. Data were calculated as percentages relative to the respective basal accumulations in the control or PCPA group. Each bar represents the mean \pm SEM $(N=6)$. PCPA treatment had no significant effect on basal $\left[{ }^{3} \mathrm{H}\right] \mathrm{CDP}$-diacylglycerol accumulation in either tissue; such basal effects being, respectively, $8194+806$ v. $8555+1657$ for control versus PCPA in frontal cortex, and $8026+1295$ v. 8139+1642 for control versus PCPA in hippocampus. Each drug induced significant accumulations of $\left[^{3} \mathrm{H}\right] \mathrm{CDP}$-diacylglycerol in either the control or PCPA tissues (ANOVA, $p<0.0001$ for each drug). PCPA partially reduced FLX and MAP effects but did not eliminate any of the drug effects: ${ }^{* *} p<0.001$, compared by posthoc Tukey tests.

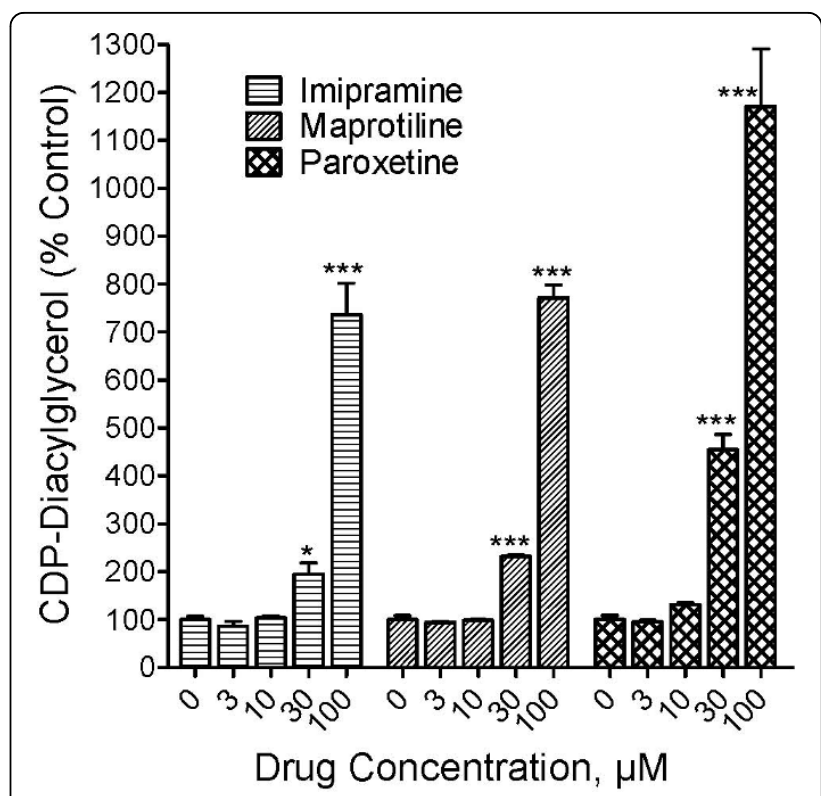

Figure 2 Effects of antidepressant agents on $\left[{ }^{3} \mathrm{H}\right] \mathrm{CDP}$ diacylglycerol synthesis in PC12 cells. PC12 cells were prelabeled with $\left[{ }^{3} \mathrm{H}\right]$ cytidine for $30 \mathrm{~min}$ and cells in different culture wells incubated with various concentrations of the antidepressant drugs imipramine, paroxetine or maprotiline. $\left[{ }^{3} \mathrm{H}\right] \mathrm{CDP}$-diacylglycerol was determined after $3 \mathrm{~h}$. Data were calculated as percentages relative to the control incubations that received no drug treatment. Each bar represents the mean \pm SEM ( $N=3$ experiments). The drug treatments increased $\left[{ }^{3} \mathrm{H}\right] \mathrm{CDP}$-diacylglycerol significantly (ANOVA, $p$ $<0.0001$ for each drug). Posthoc Dunnett tests showed statistically significant increases in CDP-diacylglycerol at 30 and $100 \mu \mathrm{M}$. ${ }^{*} \mathrm{p}<$ $0.05 ;{ }^{* * *} p<0.001$, compared to controls.

phosphatidylinositides in $\mathrm{PC} 12$ cells, another batch of the cells was prelabeled with $\left[{ }^{3} \mathrm{H}\right]$ inositol and aliquots tested with the drugs. Maprotiline and imipramine significantly and dose-dependently increased phosphatidylinositide levels in PC12 cells (Fig. 3). The effects of imipramine were statistically significant at concentrations of $1 \mu \mathrm{M}$ and higher, while the effects of maprotiline became significant at $3 \mu \mathrm{M}$ and higher concentrations. Ten micromolar and higher concentrations of fluoxetine and paroxetine were also tested for effects on phosphatidylinositides; while the 10 and 30 $\mu \mathrm{M}$ concentrations showed significant enhancement of phosphatidylinositide synthesis, the $100 \mu \mathrm{M}$ and higher concentrations caused a reduction of labeling below control levels, suggesting possible toxicity at the higher concentrations (data not shown). Taken together, the two neurolipid results (Figs. 2 and 3) suggest that antidepressants can increase CDP-diacylglycerol synthesis which translates to increased phosphatidylinositide synthesis in PC12 cells. 


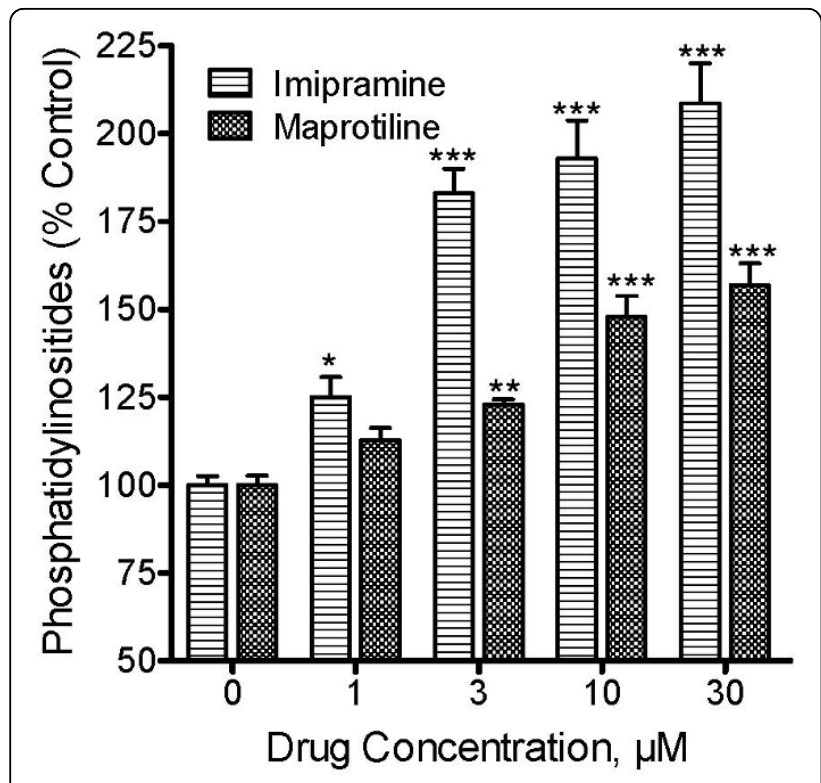

Figure 3 Effects of antidepressant agents on phosphatidylinositide synthesis in PC12 cells. PC12 cells were labeled with $\left[{ }^{3} \mathrm{H}\right]$ inositol and cells in different culture wells incubated with various concentrations of selected antidepressant drugs. After $3 \mathrm{~h}$, accumulated $\left[{ }^{3} \mathrm{H}\right]$ phosphatidylinositides were determined and the data calculated as percentages relative to control. Each bar represents the mean \pm SEM ( $N=3$ experiments). Each drug treatment increased the levels of $\left[{ }^{3} \mathrm{H}\right]$ phosphatidylinositides significantly and concentration-dependently (ANOVA, P $<0.0001$ for each drug). Posthoc Dunnett tests showed statistically significant increases in phosphatidylinositides at 1-30 $\mu \mathrm{M}$ for imipramine and at 3-30 $\mu \mathrm{M}$ for maprotiline. ${ }^{*} \mathrm{p}<0.05$; ${ }^{* *} \mathrm{P}<$ $0.01 ;{ }^{* * *} \mathrm{p}<0.001$; compared to controls.

\section{Antidepressants increase CDP-diacylglycerol synthase activity in mouse frontal cortex}

The enzyme activity of CDP-diacylglycerol synthase (CDS) was determined by measuring the rate of incorporation of tritiated CTP into CDP-diacylglycerol, and the results are shown in Fig. 4. Each of the antidepressants, imipramine, paroxetine, and maprotiline, significantly increased CDS activity (ANOVA, $\mathrm{p}<0.001$ for each drug). The posthoc Dunnett tests showed that the effects of each drug attained statistical significance at concentrations as low as $3 \mu \mathrm{M}$, and then peaked right afterwards at $10 \mu \mathrm{M}$ (imipramine) or $30 \mu \mathrm{M}$ (paroxetine and maprotiline). Thus, drug stimulation of CDS activity may underlie the positive drug effects on CDP-diacylglycerol synthesis.

\section{Discussion}

The classic action of antidepressants is to inhibit the reuptake of monoamines which leads to increased synaptic levels of the transmitters. The subsequent postsynaptic actions of the monoamines on their cognate signaling systems may then lead on to produce the clinical antidepressant effect [17-19]. However, such postsynaptic actions

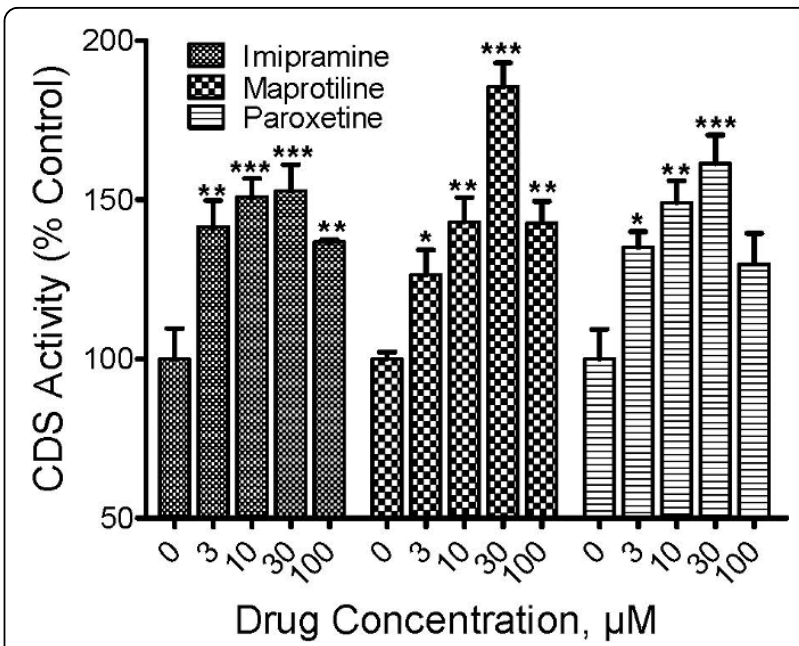

Figure 4 Antidepressant drug effects on CDP-diacylglycerol synthase activity in mouse cortex tissues. The enzymatic activity of CDP-diacylglycerol synthase (CDS) was measured in mouse cortical tissue preparations by determining the incorporation of radiolabeled cytidine derived from $5-\left[{ }^{3} \mathrm{H}\right] \mathrm{CTP}$ into CDPdiacylglycerol. Antidepressant agents were tested at concentrations ranging from $1 \mu \mathrm{M}$ to $100 \mu \mathrm{M}$. Data from each assay were normalized against the control samples by calculating the percentages shown. Each bar is the mean \pm SEM ( $N=3$ experiments). One-Way ANOVA analyses for each drug showed significant effects for imipramine $(p<0.001)$, maprotiline ( $p<$ $0.0001)$, and paroxetine $(p<0.01)$. Posthoc Dunnett tests showed that imipramine and maprotiline elicited significant effects at 3-100 $\mu \mathrm{M}$ concentrations while with paroxetine significant effects were evident at concentrations of $3-30 \mu \mathrm{M} .{ }^{*} \mathrm{p}<0.05$; $^{* *} \mathrm{P}<0.01$; $^{* *} \mathrm{p}<$ 0.001 , compared to controls.

have not been fully elucidated, although various tertiary signaling effects ranging from alterations of ion channel activity to modulation of protein kinases and gene transcription have been proposed [17,20-22]. Taking clues from a recent study showing that antidepressants concentration-dependently increase the levels of CDP-diacylglycerol and phosphatidylinositides in brain tissue preparations [2], we have now addressed the question of the extent to which this neurolipid effect may involve actions of the monoamine transmitters. The data demonstrate that various antidepressants increase phosphatidylinositol and CDP-diacylglycerol synthesis probably through stimulation of the enzymatic activity of CDS, the enzyme that synthesizes CDP-diacylglycerol. While not all antidepressant agents depend on serotonin signaling for their actions [9], a demonstration that the neurolipid effects of selective serotonin reuptake inhibitors involves multiple mechanisms should suffice as proof of the concept that not all actions of antidepressants depend on monoamine reuptake inhibition.

PCPA is often used to deplete tissues of serotonin content either in vivo or in vitro [7-9]. Protocols used here were similar to those used in numerous other 
studies some of which had the residual content of serotonin assayed to assure the expected depletion. Thus, even though we did not measure residual serotonin in the present study, there is strong precedent to assume that the agent worked as expected. Moreover, the significant reduction of the effect of fluoxetine (a selective serotonin reuptake inhibitor) in the PCPA-treated tissues supports the presumption that there was depletion of the monoamine. Unlike the fluoxetine results, there was no inhibition of imipramine (a serotonin/norepinephrine reuptake inhibitor) in any tissue, or of maprotiline (a norepinephrine reuptake inhibitor) in the frontal cortex, thus indicating that the actions of these agents on CDP-diacylglycerol or phosphatidylinositide synthesis do not require serotonin. A desirable complementary experiment would be to test if other tissues that are depleted of norepinephrine would show reductions in imipramine or maprotiline responses.

PC12 cells are widely used as a model of neuronal cell metabolism $[23,24]$. The primary reason we chose PC12 cells was to use a model system that represents practically complete lack of endogenous monoamines, notably serotonin and norepinephrine [6]. The marked and dose-dependent stimulation of CDP-diacylglycerol and phosphatidylinositide synthesis by imipramine as well as maprotiline and paroxetine in PC12 cells implies that monoamine neurotransmitters do not play a major role in the nucleolipid effects of the drugs. Interestingly, there was no significant effect of the drugs on inositol phosphate accumulation in PC12 cells (data not shown). The accumulation of inositol phosphates requires receptor-coupled stimulation of phospholipase C. Hence, while the antidepressants are able to enhance the production of substrate for the phospholipase $\mathrm{C}$ reaction, the drugs are apparently incapable by themselves to induce the breakdown of these substrates into active second messengers. This observation is in agreement with our previous proposition of a tandem signaling model for antidepressant-monoamine transmitter function. By this model, the antidepressants increase the availability of phosphatidylinositide substrates and then enhance the synaptic levels of the monoamines which then act on their cognate postsynaptic receptors to convert the phosphatidylinositide substrates into functional second messengers.

It was noted that the antidepressant drugs significantly enhanced phosphatidylinositide levels at concentrations that were clearly lower than the concentrations necessary to observe significant accumulations of CDP-diacylglycerol. Given that CDP-diacylglycerol synthase activity is considered to be rate-limiting, it is likely that any CDP-diacylglycerol formed is quickly converted to phosphatidylinositide. As such, accumulation of CDP-diacylglycerol may not become evident until the mechanism for synthesizing phosphatidylinositides begins to saturate at the higher drug concentrations. Additionally, phosphatidylinositol is able to accumulate because, as explained above, there is no mechanism to stimulate the activity of phospholipase $\mathrm{C}$ which is required to break down the phospholipid. Based on the tandem signaling model, one may predict that in the in vivo environment the direct CDP-diacylglycerol effect and the indirect monoamine reuptake effects of the antidepressant drugs would work in concert to enhance both the generation of substrate and the receptor-mediated release of intracellular second messengers.

Following the foregoing results, it still remained to be investigated how the antidepressants increase the levels of the neurophospholipids in a direct manner that may not be dependant on monoamine reuptake inhibition. First, we considered if this action was related to the lipidosis that has been associated with a number of amphiphilic compounds, a group of chemical structures that includes the tricyclics and several other antidepressants. Amphiphiles are thought to induce lipidosis (nonspecifically increased lipid synthesis) through inhibition of phospholipases that then progresses to the inhibition of phospholipid degradation [25-27]. Other observations suggest that increased cellular phosphatidylinositide levels have an inductive effect that increases non-phosphatidylinositide-derived glycerolipid synthesis [28]. If so, then a primary action of antidepressants on CDPdiacylglycerol synthesis could lead to increased phosphatidylinositide synthesis, which may then enhance the synthesis of other non-phosphatidylinositide-containing lipids.

It is still unclear if imipramine or any of the other agents interact directly with the phospholipids to prevent their degradation or inhibit phospholipases [29]. If the tested antidepressant drugs induced phosphatidylinositide accumulation solely through inhibition of phosphatidylinositide metabolism, then there should not have been an increase in CDP-diacylglycerol, which is upstream of phosphatidylinositol and whose levels are tightly controlled by the rate-limiting activity of CDS. Moreover, in brain slices, co-incubation of antidepressant with direct agonists of $5 \mathrm{HT}_{2}$ receptors resulted in enhanced accumulations of inositol phosphates over and above the effects due to agonist alone, implying that phosholipase $\mathrm{C}$ may not have been inhibited (or at least that enzyme stimulation by a coupled receptor was not prevented) [3]. Taken together, it appears that enhanced synthesis rather than inhibited degradation may explain the observed drug-induced increases in the levels of signaling phospholipids.

Based on the observation that chemically diverse antidepressants increased the synthesis of the phospholipids, we hypothesized that the drugs enhance the activity of 
the phospholipid synthesizing enzymes. This prompted the need to investigate the effects of the drugs on CDPdiacylglycerol synthase activity. CDS is reported to have high activity in the brain based on distribution analysis in rodent tissues [30]. Further, the cortex was selected for testing seeing that cognitive abnormalities such as hopelessness, memory impairments, suicidality and guilt in many depressed patients are thought to be associated with, or mediated through, the frontal cortex region of the brain. In general, the cortex might also regulate the emotional behavior abnormalities [31]. Although the tested drugs were chemically different, the drugs shared a common enhancing effect on CDS activity in the cortex. CDS activity was increased at drug concentrations of $3 \mu \mathrm{M}$ and above, which is consistent with our previous report where the antidepressants increased CDPdiacylglycerol accumulation in rat cortex slices at concentrations of 1-3 $\mu \mathrm{M}$ and above [2]. That all three tested agents enhanced the enzymatic activity of CDS provides a plausible explanation for the enhanced synthesis of CDP-diacylglycerol and phosphatidylinositides. The detailed mechanism by which the drugs induce CDS activity, however, remains to be explored.

One concern about these observations was the potential toxicity of the antidepressants given that the effective concentrations were in the micromolar range (3-300 $\mu \mathrm{M})$. A previous report showed that antidepressants such as fluoxetine (selective serotonin reuptake inhibitor) and amitriptyline (non selective reuptake inhibitor) did not adversely affect cell survival of PC12 cells up to $100 \mu \mathrm{M}$ for 24 or $48 \mathrm{~h}$ incubation periods [32]. These drugs even appeared to exert a neuroprotective effect on PC12 cells against neurotoxic insults like $200 \mu \mathrm{M}$ hydrogen peroxide by upregulating superoxide dismutase activity [32]. In another recent study examining the anti-inflammatory properties of tricyclic antidepressants, concentrations of 10 or $20 \mu \mathrm{M}$ imipramine did not reduce cell viability in the MTT assay in microglia and astrocytes incubated in vitro for up to $24 \mathrm{~h}$ [33]. In humans undergoing therapy with imipramine, drug levels reach on average $0.54 \mu \mathrm{M}$ in the plasma [34,35]. Imipramine and similar drugs, however, accumulate in brain tissue 32 -fold higher than the level in the plasma or the serum [36]. If so, then the final concentrations to which the brain is exposed are actually comparable to the concentrations of imipramine that showed significant effects in each of the present measures.

\section{Conclusions}

In conclusion, the results of this study raise the possibility that the neurolipid effects of antidepressant agents, particularly on CDP-diacylglycerol and phosphatidylinositide synthesis, may be independent of monoamine transmitter action. Given that resting cellular levels of
CDP-diacylglycerol are thought to be rather low, and that CDS activity is the rate - limiting step in CDP-diacylglycerol synthesis, enhancing the activity of CDS appears to be a logical or plausible explanation for the effect of antidepressants on CDP-diacylglycerol and phosphatidylinositide synthesis.

\section{Acknowledgements}

This research was supported by grant \#R01DA017614 from the US National Institutes of Health.

\section{Author details}

'Laboratory of Integrative Neuropharmacology, Department of Pharmaceutical Sciences, Thomas Jefferson University School of Pharmacy, Philadelphia, Pennsylvania, USA. ${ }^{2}$ Department of Pharmaceutical Sciences, University of Maryland, Baltimore, Maryland, USA.

\section{Authors' contributions}

MAA participated in experimental design, conducted the experiments, and drafted the manuscript. ASU designed the study, and participated in data analysis, writing of the manuscript, and securing funds for the study. Both authors read and approved the final manuscript.

Received: 27 May 2009

Accepted: 27 January 2010 Published: 27 January 2010

\section{References}

1. Carlezon WA Jr, Mague SD, Parow AM, Stoll AL, Cohen BM, Renshaw PF: Antidepressant-like effects of uridine and omega-3 fatty acids are potentiated by combined treatment in rats. Biol Psychiatry 2005, 57:343-350.

2. Tyeryar KR, Vongtau HO, Undieh AS: Diverse antidepressants increase CDP-diacylglycerol production and phosphatidylinositide resynthesis in depression-relevant regions of the rat brain. BMC Neurosci 2008, 9:12.

3. Tyeryar KR, Undie AS: Tandem regulation of phosphoinositide signaling and acute behavioral effects induced by antidepressant agents in rats. Psychopharmacology (Berl) 2007, 193:271-282

4. Pandey GN, Pandey SC, Davis JM: Effect of desipramine on inositol phosphate formation and inositol phospholipids in rat brain and human platelets. Psychopharmacol Bull 1991, 27:255-261.

5. Pandey SC, Davis JM, Schwertz DW, Pandey GN: Effect of antidepressants and neuroleptics on phosphoinositide metabolism in human platelets. J Pharmacol Exp Ther 1991, 256:1010-1018.

6. Schonn JS, Desnos C, Henry JP, Darchen F: Transmitter uptake and release in PC12 cells overexpressing plasma membrane monoamine transporters. J Neurochem 2003, 84:669-677.

7. Koe BK, Weissman A: p-Chlorophenylalanine: a specific depletor of brain serotonin. J Pharmacol Exp Ther 1966, 154:499-516.

8. Kusumi I, Mikuni M, Kuroda Y, Takahashi K: Subchronic administration of para-chlorophenylalanine enhances serotonin-stimulated phosphoinositide hydrolysis in rat hippocampal slices. $J$ Neural Transm Gen Sect 1990, 80:181-188.

9. Page ME, Detke MJ, Dalvi A, Kirby LG, Lucki I: Serotonergic mediation of the effects of fluoxetine, but not desipramine, in the rat forced swimming test. Psychopharmacology (Berl) 1999, 147:162-167.

10. Undie AS: Relationship between dopamine agonist stimulation of inositol phosphate formation and cytidine diphosphate-diacylglycerol accumulation in brain slices. Brain Res 1999, 816:286-294.

11. Undie AS, Friedman E: Stimulation of a dopamine D1 receptor enhances inositol phosphates formation in rat brain. J Pharmacol Exp Ther 1990, 253:987-992.

12. Claro E, Fain JN, Picatoste F: Noradrenaline stimulation unbalances the phosphoinositide cycle in rat cerebral cortical slices. J Neurochem 1993, 60:2078-2086.

13. Stubbs EB Jr, Agranoff BW: Lithium enhances muscarinic receptorstimulated CDP-diacylglycerol formation in inositol-depleted SK-N-SH neuroblastoma cells. J Neurochem 1993, 60:1292-1299. 
14. Saito S, Goto K, Tonosaki A, Kondo H: Gene cloning and characterization of CDP-diacylglycerol synthase from rat brain. J Biol Chem 1997, 272:9503-9509.

15. Lykidis A, Jackson PD, Rock CO, Jackowski S: The role of CDP-diacylglycerol synthetase and phosphatidylinositol synthase activity levels in the regulation of cellular phosphatidylinositol content. J Biol Chem 1997, 272:33402-33409.

16. Saito S, Sakagami H, Tonosaki A, Kondo H: Localization of mRNAs for CDPdiacylglycerol synthase and phosphatidylinositol synthase in the brain and retina of developing and adult rats. Brain Res Dev Brain Res 1998, 110:21-30.

17. Manji HK, Drevets WC, Charney DS: The cellular neurobiology of depression. Nat Med 2001, 7:541-547.

18. Nestler EJ, Gould E, Manji H, Buncan M, Duman RS, Greshenfeld HK, et al: Preclinical models: status of basic research in depression. Biol Psychiatry 2002, 52:503-528.

19. Morilak DA, Frazer A: Antidepressants and brain monoaminergic systems: a dimensional approach to understanding their behavioural effects in depression and anxiety disorders. Int I Neuropsychopharmacol 2004, 7:193-218.

20. Popoli M, Brunello N, Perez J, Racagni G: Second messenger-regulated protein kinases in the brain: their functional role and the action of antidepressant drugs. J Neurochem 2000, 74:21-33.

21. Tiraboschi E, Tardito D, Kasahara J, Moraschi S, Pruneri P, Gennarelli M, et al: Selective phosphorylation of nuclear CREB by fluoxetine is linked to activation of CaM kinase IV and MAP kinase cascades. Neuropsychopharmacology 2004, 29:1831-1840.

22. Tardito D, Perez J, Tiraboschi E, Musazzi L, Racagni G, Popoli M: Signaling pathways regulating gene expression, neuroplasticity, and neurotrophic mechanisms in the action of antidepressants: a critical overview. Pharmacol Rev 2006, 58:115-134.

23. Richardson UI, Watkins CJ, Pierre C, Ulus $\mathrm{H}$, Wurtman RJ: Stimulation of CDP-choline synthesis by uridine or cytidine in $\mathrm{PC} 12$ rat pheochromocytoma cells. Brain Res 2003, 971:161-167.

24. Richardson UI, Wurtman RJ: Polyunsaturated fatty acids stimulate phosphatidylcholine synthesis in PC12 cells. Biochim Biophys Acta 2007, 1771:558-563.

25. Hostetler KY, Matsuzawa Y: Studies on the mechanism of drug-induced lipidosis. Cationic amphiphilic drug inhibition of lysosomal phospholipases A and C. Biochem Pharmacol 1981, 30:1121-1126.

26. Hurwitz R, Ferlinz K, Sandhoff K: The tricyclic antidepressant desipramine causes proteolytic degradation of lysosomal sphingomyelinase in human fibroblasts. Biol Chem Hoppe Seyler 1994, 375:447-450.

27. Kucia K, Malecki A, Gabryel B, Trzeciak HI: Effect of antidepressants on the phospholipase $\mathrm{A} 2$ activity in plasma membranes of the rat brain cortex. Pol J Pharmacol 2003, 55:5-15.

28. Matsuzawa Y, Poorthuis BJ, Hostetler KY: Mechanism of phosphatidylinostiol stimulation of lysosomal bis (monoacylglyceryl) phosphate synthesis. J Biol Chem 1978, 253:6650-6653.

29. Xia Z, Ying G, Hansson AL, Karlsson H, Xie Y, Bergstrand A, et al: Antidepressant-induced lipidosis with special reference to tricyclic compounds. Prog Neurobiol 2000, 60:501-512.

30. Inglis-Broadgate SL, Ocaka L, Banerjee R, Gaasenbeek M, Chapple JP, Cheetham ME, et al: Isolation and characterization of murine Cds (CDPdiacylglycerol synthase) 1 and 2. Gene 2005, 356:19-31.

31. Berton O, Nestler EJ: New approaches to antidepressant drug discovery: beyond monoamines. Nat Rev Neurosci 2006, 7:137-151.

32. Kolla N, Wei Z, Richardson JS, Li XM: Amitriptyline and fluoxetine protect PC12 cells from cell death induced by hydrogen peroxide. J Psychiatry Neurosci 2005, 30:196-201.

33. Hwang J, Zheng LT, Ock J, Lee MG, Kim SH, Lee HW, et al: Inhibition of glial inflammatory activation and neurotoxicity by tricyclic antidepressants. Neuropharmacology 2008, 55:826-834.

34. Wille SM, Cooreman SG, Neels HM, Lambert WE: Relevant issues in the monitoring and the toxicology of antidepressants. Crit Rev Clin Lab SCi 2008, 45:25-89.

35. Winek CL, Wahba WW, Winek CL Jr, Balzer TW: Drug and chemical bloodlevel data 2001. Forensic Sci Int 2001, 122:107-123.

36. Devane CL, Simpkins JW, Stout SA: Cerebral and blood pharmacokinetics of imipramine and its active metabolites in the pregnant rat. Psychopharmacology (Berl) 1984, 84:225-230. doi:10.1186/1471-2202-11-10

Cite this article as: Aboukhatwa and Undieh: Antidepressant stimulation of CDP-diacylglycerol synthesis does not require monoamine reuptake inhibition. BMC Neuroscience 2010 11:10.

\section{Publish with Biomed Central and every scientist can read your work free of charge}

"BioMed Central will be the most significant development for disseminating the results of biomedical research in our lifetime. "

Sir Paul Nurse, Cancer Research UK

Your research papers will be:

- available free of charge to the entire biomedical community

- peer reviewed and published immediately upon acceptance

- cited in PubMed and archived on PubMed Central

- yours - you keep the copyright 